\title{
Initiating an Outcome-Based Education Environment at a Higher Education Institution: A Case Study
}

\author{
Amira Bibo Sallow ${ }^{1}$, Muaid Abdlqader ${ }^{2}$, Nada E. Tawfiq ${ }^{1}$, Mohammed Ali Shallal ${ }^{3}$ \\ ${ }^{1}$ Computer Science Department $\quad{ }^{2}$ Centre of Assessment \& QA $\quad{ }^{3}$ Scientific Research \& Development Centre \\ Nawroz University, Duhok, Kurdistan Region - Iraq
}

\begin{abstract}
The paper presents a brief account of a case study reflecting steps that may be found useful as guidelines for initiating an outcome-based education (OBE) environment for programs at a higher education institution (HEI). It highlights the broad steps in the process of establishing a framework for a curriculum of an undergraduate program in light of current trends, with suggestions that may be helpful in paving the way for a HEI to follow, should such an aim be desired. A sample of a computer science (CMSC) program is used as an example to illustrate the steps followed in accordance with relevant academic accreditation criteria and quality assurance (QA) standards.
\end{abstract}

KEYWORDS: Nawroz niversity (NzU), Outcome-Based Education, Curriculum, Academic Accreditation.

\section{Introduction}

OBE is being adopted at a fast pace at HEIs, becoming a focal point for higher education reforms in countries worldwide. Indeed, all academic accreditation agencies and bodies advocate the inclusion of OBE features in curriculum structures as an essential requirement.

The OBE model is based on a student centred learning (SCL) philosophy in that it focuses on the outcomes. With that principle in mind, the structure and frameworks of various program curricula are accordingly designed.

A curriculum may be considered to include the following components: ${ }^{[1]}$

- Program Educational Objectives (PEOs)

- Statements of Program Learning Outcomes (PLOs)

- LOs and contents for each Course in the curriculum (CLOs)

- Teaching \& Learning (T\&L) processes

- Means of assessment.

The overall alignment of these components is essential to ensure that what is taught, what is learnt, and what is assessed are in harmony and supported by appropriate means of demonstrating the evidence and providing feedback. [2]

Academic Journal of Nawroz University

(AJNU) Volume 8, No 3 (2019).

Regular research paper : Published 27 August 2019

Corresponding author's e-mail : mashallal44@gmail.com

Copyright (C2019 Amira Bibo Sallow 1, Muaid Abdlqader 2,

Nada E. Tawfiq ${ }^{1}$, Mohammed Ali Shallal ${ }^{3}$.

This is an open access article distributed under the Creative

Commons Attribution License.
The paper aims at highlighting some OBE issues by presenting a procedure showing a sequence of steps that may be found useful as guidelines to structure a framework for an OBE curriculum at a HEI, in light of appropriate academic accreditation standards. Such a curriculum structure is based on a semester-based approach in accordance with the decree issued by the Ministry of Higher Education requiring HEIs to adopt a semester-based system. Problems would be anticipated in such a conversion and the paper attempts to outline some these problems and suggest some subsequent related issues to be taken into consideration.

Section 2 presents a brief account of the steps followed in the current study to establish the sought framework.

Section 3 describes the establishment of a curriculum main structure and the accompanying alignment matrices, as well as the preparation for the development of a basic course/program catalog.

Section 4 presents some issues that ought to be taken into consideration before and during the implementation phase of switching from a current scheme to one similar to the proposed in this study.

Section 5 includes a summary with conclusions that may be taken into consideration for the phases that follow.

The paper terminates with a number of appendices related in some parts to aspects of $\mathrm{NzU}$ and referred to in the remaining sections. Appendix VI shows a short glossary of some terms used in the paper.

\section{Outline of the Adopted Procedure}

After establishing the HEI's mission, goals and objectives (appendix II), a possible simplified number of steps ${ }^{[3,4]}$ which may be adopted for the process of 
initial program curriculum development follow (a semester-based scheme with the adoption of credithours (CrHrs), also known as semester credits, is assumed, appendix VI):

a. Establish program mission statement(s) and PEOs.

b. Define PLOs and map with PEOs as an alignment matrix.

c. Establish the overall curriculum framework and the schedule of courses distributed over the semesters, bearing in mind the number of CrHrs required for graduation, prerequisite requirements for each component, and the CrHrs for each curriculum component.

d. Adopt a suitable course code policy.

e. Establish all the alignment matrices involving courses with PLOs.

f. Prepare CLOs for all courses and include them in course plans.

g. Include all above components in a program catalog.

These steps are not necessarily independent or in strict sequence, as some of them may be interlinked.

Naturally, preparing for the implementation of the above steps requires the organization of appropriate seminars and workshops with the aim of faculty capacity building and preparation in a timely manner. Such seminars and workshops were organized at $\mathrm{NzU}$ before and during the curriculum design process over a period of two years. Below are examples of titles of some implemented main themes, each of which may have required a number of sessions, with the participation of academic administrators and faculty from selected programs:

i. Initiating $\mathrm{OBE}$

ii. Alignment aspects of teaching, learning and assessment

iii. Preparation of course plans and course reports/files

iv. Assessment of learning at course and program levels

v. Academic program accreditation issues

vi. Restructuring program curricula

\section{An Illustrative Curriculum Structure}

A CMSC version of a program is used as an example to illustrate the issues involved in the development of a curriculum framework based on relevant accreditation criteria, in this case ABET CAC (Computing Accreditation Commission, 2018-2019 version 1.0).[5]

The curriculum structure is derived in light of CAC criteria 2, 3, and 5 (general and program specific, appendix I). The objectives and LOs involved are derived based on a sequence outlined in the outcomes pyramid that has the HEI's mission and objectives at the top. Subsequently, it is necessary to establish the alignment of these LOs with each other, and a common way of establishing this alignment is through suitable matrices.

\subsection{The development of the Structure}

Present curricula of many HEIs' programs are based on the relatively rigid predetermined year structure. As part of the reform process, the opportunity is taken to revise the structure with the following ideas in mind:

- conversion to the more up-to-date structure of a semester of 15 weeks of instruction (excluding assessment).

- inclusion of a certain degree of flexibility by including electives.

- curriculum modification in light of relevant accreditation criteria \& international trends.

Accordingly, a framework based on the following components is targeted: [6,10]

- General education (GE) courses with a possible list of electives.

- College requirements courses.

- Department or specialization courses with a list of electives.

- Supplementary courses, where necessary and/or convenient.

Elective lists could be dynamic in the sense that a list's contents and the courses from that list that are actually offered may vary from one semester to another, as the situation demands and/or as seen appropriate.

The essential objectives and LOs taken into consideration at the program level, in accordance with ABET CAC criteria, are the PEOs and PLOs. These are shown in appendix III together with the matrix aligning them. The following notes may be made regarding the list of PLOs given:

- the list of PLOs may contain LOs that are also related to the GE courses (for example PLOs d,e, and $\mathrm{f}$ in the list), which is a common practice.

- a program may add more PLOs to the list or modify the existing ones.

Putting these issues and the steps outlined in section 2 together, appendix IV shows:

- a proposed structure for a program curriculum,

- a schedule of courses distributed over semesters,

- an overall alignment matrix of program courses with the PLOs.

The following observations are worth mentioning regarding the structure of the curriculum:

- pre-requisites for all courses in the structure are specified. This would also become essential 
should the structure be subjected to a more flexible scheme based on the accumulation of credit units in the future, where students may be given options for choosing different paths through the curriculum.

- the modular form of the curriculum structure, where most courses carry a weight of three CrHrs, which is a common attribute allowing flexibility that is also useful for facilitating future changes and/or modifications.

\subsection{Assessment and the establishment of a Program Catalog}

The course/program catalog is one of the important documents demanded by academic accreditation standards and QA agencies.[9,12] An initial version of such a catalog for a program may be constructed by combining the contents of all the appendices presented thus far, with appropriate course plans for each course/component in the curriculum structure.

A course plan (also called course syllabi) is a tool that communicates to students the course information specific to the course before the semester starts. Each course plan may include the course aims and objectives with the LOs, course contents, the alignment matrices linking each course LOs to the main PLOs, the course contents to the CLOs, and the assessment components and types for the course. $[2,8,12]$

It is essential to diversify student assessment types that are appropriate for each of the curriculum components/ courses concerned. Such a diversification would help in providing the evidence for the level of attainment of CLOs. The types of assessment may vary from one component/course to another depending on the nature of LOs and/or characteristics of the component. Adequate formative assessments, in addition to the summative ones, are to be included in order to provide feedback for students as well as lecturers involved during the semester.

Another important tool also commonly used is the course report, which represents a lecturer's review of the way the course was structured, taught and assessed at the end of a semester, after the announcement of final examination results. The course report thus serves as a feedback tool to show, among other things, the level of achievement of the CLOs, and whether any changes to the course are needed. The accumulation of course reports would form the course file for that course. $[2,8]$

Suitable course plan and course report formats may be determined in accordance with typical accreditation standards requirements (e.g., CAA[8] : appendix V).

\section{Implementation Issues:}

Transformation from current curriculum structures, particularly when the current one is based on a year structure of subjects as is the case in some programs, is not expected to be a smooth process. It is suggested that such a transformation be started with newly admitted first year students and moving with the new structure as students' progress.

Difficulties and problems are expected to appear along the path during the various phases due to cases related to students from previous batches who may have to repeat a whole year, or some subjects or courses. The nature of these problems would depend on the program discipline and the extent of curriculum changes involved.

For a semester-based scheme to be implemented successfully, the following are some issues that need to be taken into consideration:

i. Specifying prerequisite/corequisite courses and conditions for all courses/components to be shown in the curriculum structure (appendix IV). The question of allowing a student to enroll in a course without having satisfied its prerequisite requirements ought to be dealt with.

ii. Allowing students who fail in any course to re-sit the examination for that course after the final examinations of that semester and before the commencement of the following semester with the adjustment of the academic calendar accordingly.

iii. Finding a solution to the situation that may currently exist where a student is allowed to 'carry' a course from one semester to another even if $s /$ he has not satisfied the requirements (e.g. passed) that course.

iv. Dealing with problems resulting from situations outlined in i-iii above, and other possibly unforeseen situations, will certainly require careful analyses and setting required regulations. Further problems to be dealt with concern cases appearing from situations of overlap between curriculum versions (with students repeating a year or some courses) during the stages of implementing the new curriculum until it becomes the only version being implemented covering the full program duration.

\section{Summary and Conclusions}

- The ideas \& concepts presented in this work are well-known and established in HEIs worldwide. The paper has concentrated on the foundational phase of constructing a curriculum structure based on an OBE environment, without tackling implementation details which would certainly lead to regular revisions and/or improvements in the curricula. 
- It is not claimed that the computer science program structure presented and used as an illustration in this paper to be ready and suitable for implementation as it is. Further analyses, modifications, improvements and approvals may be required.

- Such a proposed curriculum structure and OBE approach may be implemented starting with first year students from the start of an academic year pending the provision of requirements and possible modifications based on approvals by the HEI authorities. Further issues need to be given a special consideration during the implementation phases that follow to build on what is presented in this paper, including T\&L methodologies, appropriate assessment processes, psychometrics, preparation of required documents and regulations. Needless to say, improvements based on feedback from various sources and stakeholders will be required over a period of time to come.

- The concepts presented are compatible with general accreditation standards. Naturally each program has to base its structure and attributes on standards appropriate to that program.

- The concepts presented may be adapted to suit schemes other than the CrHrs assumed in this work, for example the ECTS credits that are implemented under the Bologna Process. ${ }^{[9,13]}$ Of course modifications to the program structure would then be needed.

- It is recommended to plan for the adoption of a scheme based on the accumulation of CrHrs/credits, where flexibility is introduced into the curricula by providing the students with more autonomy in choosing the desired paths, instead of current rigid predetermined semester/year structures. Such a scheme would necessarily require the specification and enforcement of the prerequisite conditions for all components in the structure with clear pathways defined towards the target for graduation. Inclusion of tracks/concentrations may also be considered to provide more flexibility [6].

- Success in achieving desired aims \& targets in a HEI requires an environment with a culture where the responsibility is shared by everyone and a certain level of motivation to exit.

\section{Acknowledgements}

Key concepts underpinning the curriculum development in this paper were identified from the literature. The authors would like to express their thanks and appreciation to faculty members at NzU for their contributions, discussions and opinions expressed.

\section{References}

1. CEA, Commission on English Language Program Accreditation, http ://www.cea-accredit.org

2. Mohammed Ali Shallal (2018). Alignment of Curriculum Elements at the Course Level: Two Useful Tools. Academic Journal of Nawroz University (AJNU) Volume 7, No 1, 85-92.

3. William G. Spady (1994). Outcome -based Education: Critical issues and Answers. The American Association of School Administrators,

4. Muhammad H. Rashid (2013). The Process of OBE Implementation, Assessment and Evaluations. University of West Florida, American Society for Engineering Education.

5. ABET CAC, Accreditation Board for Engineering and Technology, http : / /www.abet.org

6. Mohammed Ali Shallal (2018). Trends in Undergraduate Program Curriculum Frameworks. Academic Journal of Nawroz University (AJNU) Volume 7, No 3, 228-234.

7. Curriculum Guidelines for UG Degree Programs in Computer Science, ACM, IEEE Computer Society, December 2013.

8. CAA, Commission for Academic Accreditation Standards, UAE, http ://www.caa.ae

9. The European Credit Transfer and Accumulation System (ECTS), ECTS Users' Guide 2015

10. Al Ain University of Science \& Technology, http : //www.aau.ac.ae

11. Qatar University Academic Catalog, http:/ / www.qu.edu.qa

12. Standards and Guidelines for Quality Assurance in the European Higher Education Area (ESG). (2015), Brussels, Belgium.

13. Mohammed Ali Shallal (2019). The Bologna Process: Question of Priorities and Relevance. Academic Journal of Nawroz University (AJNU) Volume 8, No 2, 1-5.

\section{Appendices}

(Some appendices may be subject to modifications and approvals in light of the HEI regulations)

Appendix I ABET CAC Criteria

Appendix II NzU Vision, Mission, Goals \& Objectives

Appendix III CMSC Mission, PEOs and PLOs Appendix IV CMSC program structure Appendix V Course Plan \& Course Report CAA (2019) Annexes

Appendix VI Definition of terms 


\section{Appendix I ABET CAC 2018-2019 version 1.0 [5]}

\section{General Requirements Criteria 2,3 and 5}

Criterion 2. Program Educational Objectives

The program must have published program educational objectives that are consistent with the mission of the institution, the needs of the program's various constituencies, and these criteria. There must be a documented, systematically utilized, and effective process, involving program constituencies, for the periodic review of these program educational objectives that ensures they remain consistent with the institutional mission, the program's constituents' needs, and these criteria.

\section{Criterion 3. Student Outcomes}

The program must have documented student outcomes that prepare graduates to attain the program educational objectives. There must be a documented and effective process for the periodic review and revision of these student outcomes.

The program must enable students to attain, by the time of graduation:

a. An ability to apply knowledge of computing and mathematics appropriate to the program's student outcomes and to the discipline

b. An ability to analyze a problem, and identify and define the computing requirements appropriate to its solution

c. An ability to design, implement, and evaluate a computer-based system, process, component, or program to meet desired needs

d. An ability to function effectively on teams to accomplish a common goal

e. An understanding of professional, ethical, legal, security and social issues \& responsibilities

f. An ability to communicate effectively with a range of audiences

g. An ability to analyze the local and global impact of computing on individuals, organizations, and society

h. Recognition of the need for and an ability to engage in continuing professional development

i. An ability to use current techniques, skills, and tools necessary for computing practice.

\section{Criterion 5. Curriculum}

- The program's requirements must be consistent with its program educational objectives and designed in such a way that each of the student outcomes can be attained.

- The curriculum must combine technical and professional requirements with general education requirements and electives to prepare students for a professional career and further study in the computing discipline associated with the program, and for functioning in modern society.

- The technical and professional requirements must include at least one year of up-to- date coverage of fundamental and advanced topics in the computing discipline associated with the program.

- In addition, the program must include mathematics appropriate to the discipline beyond the pre-calculus level.

- For each course in the major required of all students, its content, expected performance criteria, and place in the overall program of study must be published.

\section{Program Specific Requirements Criteria 3 and 5}

PROGRAM CRITERIA FOR COMPUTER SCIENCE AND SIMILARLY NAMED COMPUTING PROGRAMS

These program criteria apply to computing programs using computer science or similar terms in their titles.

\section{Criterion 3. Student Outcomes}

The program must enable students to attain, by the time of graduation:

a. An ability to apply mathematical foundations, algorithmic principles, and computer science theory in the modeling and design of computer-based systems in a way that demonstrates comprehension of the tradeoffs involved in design choices. [CS]

b. An ability to apply design and development principles in the construction of software systems of varying complexity. [CS]

\section{Criterion 5. Curriculum}

Students must have the following amounts of course work or equivalent educational experience:

a. Computer science: One and one-third years that must include:

- Coverage of the fundamentals of algorithms, data structures, software design, concepts of programming languages and computer organization and architecture. [CS]

- An exposure to a variety of programming languages and systems. [CS]

- Proficiency in at least one higher-level language. [CS]

- Advanced course work that builds on the fundamental course work to provide depth. [CS]

b. One year of science and mathematics:

- Mathematics: At least one-half year that must include discrete mathematics. The additional mathematics might consist of courses in areas such 
as calculus, linear algebra, numerical methods, probability, statistics, number theory, geometry, or symbolic logic. [CS]

- Science: A science component that develops an understanding of the scientific method and provides students with an opportunity to experience this mode of inquiry in courses for science or engineering majors that provide some exposure to laboratory work. [CS]

\section{Appendix II NzU Institutional Statement of Vision, Mission, Goals \& Objectives}

\section{Vision}

To be recognized as a university of high quality in the region.

Mission

Nawroz University seeks to:

a. Meet the cultural needs of Kurdistan through commitment to the educational, technological, and economic development of the society.

b. Contribute to the advancement of knowledge through quality teaching and research.

University Goals

Goal \#1: Provide high-quality and broad-based education.

Objectives:

1. Maintain quality and meet standards in teaching and learning.

2. Recruit and retain qualified and dedicated faculty and support staff.

3. Provide faculty development support and research opportunities.

Goal \#2: Provide modern facilities, resources, and support services

Objectives:

1. Maintain the use of modern instructional support facilities and services.

2. Create a healthy and attractive academic environment.

Goal \#3: Preserve and promote Kurdish values and culture.

Objectives:

1. Integrate the Kurdish culture, heritage and values into academic disciplines.

Goal \#4: Contribute to the society and community development through appropriate activities.

Objectives:

1. Participate actively in community events.

2. Improve communication channels for alumni and employers with NZU.

3. Offer continuing education opportunities for learners in the community.

\section{NZU Core Values}

1- Heritage: NzU works to catch up with developments in the world while preserving the national heritage.

2- Ethics: NzU fosters openness, honesty, and fairness in social and moral, as well as academic matters.

3- Commitment to quality: NzU applies principles of self-evaluation and continuous improvement to fulfil its goals and mission.

4-Responsibility: NzU serves Kurdistan society through quality teaching and learning, applied research, and continuing education programs.

\section{Appendix III CMSC Program Mission, PEOs and PLOs}

\section{About the CMSC Program}

The Computer Science Program offers a Bachelor of Science degree in Computer Science. This program provides graduates with quality education, training and skills enabling them to become successful professionals.

\section{CMSC Mission}

To educate students with core knowledge that forms the basis for computer software and hardware and prepare qualified graduates for professional practice to meet the needs of the community in the field of computer science.

\section{CMSC PEOs}

The undergraduate education in the NzU Computer Science Department prepares students to achieve our Program Educational Objectives (PEOs):

PEO1: Use basic science and mathematical foundations in the design of computer-based systems.

PEO2: Demonstrate depth of knowledge in CS coupled with capacity to produce feasible and reasonable solutions for computing problems.

PEO3: Adapt to new technologies, tools and methodologies to maintain their ability to respond to the challenges of a changing environment.

PEO4: Exhibit the clear communication, responsible teamwork, and professional attitudes and ethics needed to engage in successful careers.

\section{Consistency of the Program Mission and PEOs with the Mission of the Institution}

The program mission and educational objectives are consistent with those of the University.

The key sentence of the University of Nawroz's mission statement is:

"meet the cultural needs of Kurdistan through commitment to the educational, technological, and economic development of the society."

These correspond to CMSC's mission. 
"prepare qualified graduates for professional practice to meet the needs of the community in the field of computer science."

\section{CMSC PLOs}

Students graduating from the computer Science Department at $\mathrm{NzU}$ will be expected and prepared to exercise the skills and abilities (a) through (k) listed below (extracted from CAC criteria):

a. An ability to apply knowledge of computing and mathematics appropriate to the discipline.

b. An ability to analyze a problem and identify and define the computing requirements appropriate to its solution.

c. An ability to design, implement, and evaluate a computer-based system, process, component, or program to meet desired needs.

d. An ability to function effectively on teams to accomplish a common goal. e. An understanding of professional, ethical, legal, security and social issues and responsibilities.

f. An ability to communicate effectively with a range of audiences.

g. An ability to analyze the local and global impact of computing on individuals, organizations, and society.

h. Recognition of the need for and an ability to engage in continuing professional development.

i. An ability to use current techniques, skills, and tools necessary for computing practice.

j. An ability to apply mathematical foundations, algorithmic principles, and computer science theory in the modeling and design of computerbased systems in a way that demonstrates comprehension of the tradeoffs involved in design choices. [CS]

k. An ability to apply design and development principles in the construction of software systems of varying complexity. [CS]

\section{Alignment of PLOs with Program Educational Objectives}

\begin{tabular}{|c|c|c|c|c|}
\hline \multirow{2}{*}{ Program Learning Outcome } & \multicolumn{4}{|l|}{ PEOs } \\
\hline & PEO1 & PEO2 & PEO3 & PEO4 \\
\hline $\begin{array}{l}\text { a. An ability to apply knowledge of computing and mathematics } \\
\text { appropriate to the discipline }\end{array}$ & $\sqrt{ }$ & & & \\
\hline $\begin{array}{l}\text { b. An ability to analyze a problem, and identify and define the } \\
\text { computing requirements appropriate to its solution }\end{array}$ & & $\sqrt{ }$ & & \\
\hline $\begin{array}{l}\text { c. An ability to design, implement, and evaluate a computer-based } \\
\text { system, process, component, or program to meet desired needs }\end{array}$ & & $\sqrt{ }$ & & \\
\hline $\begin{array}{l}\text { d. An ability to function effectively on teams to accomplish a common } \\
\text { goal }\end{array}$ & & & & $\sqrt{ }$ \\
\hline $\begin{array}{l}\text { e. An understanding of professional, ethical, legal, security and social } \\
\text { issues and responsibilities }\end{array}$ & & & & $\sqrt{ }$ \\
\hline f. An ability to communicate effectively with a range of audiences & & & & $\sqrt{ }$ \\
\hline $\begin{array}{l}\text { g. An ability to analyze the local and global impact of computing on } \\
\text { individuals, organizations, and society }\end{array}$ & & & & $\sqrt{ }$ \\
\hline $\begin{array}{l}\text { h. Recognition of the need for and an ability to engage in continuing } \\
\text { professional development }\end{array}$ & & & & $\sqrt{ }$ \\
\hline $\begin{array}{l}\text { i. An ability to use current techniques, skills, and tools necessary for } \\
\text { computing practice. }\end{array}$ & & & $\sqrt{ }$ & \\
\hline $\begin{array}{l}\text { j. An ability to apply mathematical foundations, algorithmic principles, } \\
\text { and computer science theory in the modeling and design of computer- } \\
\text { based systems. [CS] }\end{array}$ & $\sqrt{ }$ & & & \\
\hline $\begin{array}{l}\text { k. An ability to apply design and development principles in the } \\
\text { construction of software systems of varying complexity. [CS] }\end{array}$ & & & $\sqrt{ }$ & \\
\hline
\end{tabular}




\section{Appendix IV CMSC program structure}

\begin{tabular}{|c|c|c|c|c|c|c|c|}
\hline \multirow{2}{*}{\multicolumn{4}{|c|}{ General Education Requirements (15) CrHrs }} & \multirow{3}{*}{$\begin{array}{l}\text { CMSC314 } \\
\text { CMSC312 } \\
\text { CMSC324 }\end{array}$} & \multirow{2}{*}{$\begin{array}{l}\text { Networking } \\
\text { Theory of } \\
\text { computation }\end{array}$} & \multirow{2}{*}{$\begin{array}{l}3 \\
2\end{array}$} & \multirow{2}{*}{$\begin{array}{l}\text { GCMS105 } \\
\text { MATH123 }\end{array}$} \\
\hline & & & & & & & \\
\hline Code & Name & $\begin{array}{l}\mathrm{Cr} \\
\mathrm{Hrs}\end{array}$ & Prereq & & Data Security & 3 & CMSC225 \\
\hline GKRD101 & Kurdology/Language & 3 & - & CMSC313 & Web Development & 2 & CMSC223 \\
\hline GACD104 & Academic Debate & 3 & - & CMSC322 & Android App Dev & 3 & CMSC225 \\
\hline GENG103 & English Language & 3 & - & CMSC325 & Summer training & 3 & $90 \mathrm{CrHrs}$ \\
\hline GKRD102 & $\begin{array}{lll}\text { Kurdish History \& } \\
\text { Culture }\end{array}$ & 3 & - & CMSC321 & Compilers & 3 & CMSC312 \\
\hline GCMS105 & Computer Skills & 3 & - & CMSC316 & Mini project I & 1 & $60 \mathrm{CrHrs}$ \\
\hline \multirow{2}{*}{\multicolumn{2}{|c|}{ Compulsory College Requirements }} & \multirow{2}{*}{\multicolumn{2}{|c|}{ (15) CrHrs }} & CMSC326 & Mini project II & 1 & CMSC316 \\
\hline & & & & CMSC412 & $\begin{array}{l}\text { Client-Server } \\
\text { Networks }\end{array}$ & 3 & CMSC314 \\
\hline Code & Name & $\begin{array}{l}\mathrm{Cr} \\
\mathrm{Hrs}\end{array}$ & Prereq & CMSC413 & iOS App Dev & 3 & CMSC225 \\
\hline MATH111 & Calculus I & 3 & - & CMSC422 & Digital Image Proc & 3 & CMSC311 \\
\hline MATH123 & Discrete Structures & 3 & - & CMSC414 & Operating Systems & 3 & CMSC222 \\
\hline MATH216 & Probability \& Statistics & 3 & MATH111 & CMSC411 & Intelligent Systems & 3 & CMSC121 \\
\hline CMSC315 & Num Analysis & 3 & MATH122 & CMSC415 & CS Capstone Project I & 3 & $90 \mathrm{CrHrs}$ \\
\hline PHYS211 & Physics I & 3 & MATH111 & CMSC425 & CS Capstone Project II & 3 & CMSC415 \\
\hline \multicolumn{2}{|c|}{ Specialization Compulsory Courses } & \multicolumn{2}{|c|}{ (84) CrHrs } & \multicolumn{4}{|c|}{ Elective Courses $\quad$ (9) CrHrs } \\
\hline Code & Name & $\begin{array}{l}\mathrm{Cr} \\
\mathrm{Hrs}\end{array}$ & Prereq & Code & Name & $\begin{array}{l}\mathrm{Cr} \\
\mathrm{Hrs}\end{array}$ & Prereq \\
\hline CMSC111 & Prog Fundmntls I & 3 & GCMS105 & CMSC424 & Parallel \& Distrbtd S. & 3 & CMSC414 \\
\hline CMSC121 & Prog Fundmntls II & 3 & CMSC111 & CMSC421 & Machine learning & 3 & CMSC411 \\
\hline CMSC122 & Logic design & 3 & GCMS105 & CMSC423 & Data Communication & 3 & CMSC314 \\
\hline CMSC123 & Visual prog & 3 & CMSC111 & CMSC427 & Multimedia Techlgy & 3 & GCMS105 \\
\hline CMSC211 & Data Structures & 3 & CMSC111 & CMSC428 & Data \& Web Mining & 3 & CMSC224 \\
\hline CMSC212 & Computer Org. & 3 & CMSC122 & CMSC327 & SW Project Mangmnt & 3 & CMSC225 \\
\hline CMSC221 & Algorithm A \& D & 3 & CMSC211 & CMSC328 & Simulation \& Modeling & 3 & MATH216 \\
\hline CMSC222 & Computer Arch. & 3 & CMSC212 & \multirow{3}{*}{\multicolumn{4}{|c|}{ Supplementary Courses (8) CrHrs }} \\
\hline CMSC215 & Info. Management & 3 & CMSC216 & & & & \\
\hline CMSC216 & Prog Lang. & 3 & CMSC121 & & & & \\
\hline CMSC224 & Database Systems & 3 & CMSC215 & Code & Name & $\begin{array}{l}\mathrm{Cr} \\
\mathrm{Hrs} \\
\end{array}$ & Prereq \\
\hline CMSC225 & Software Dev. & 3 & CMSC216 & MATH122 & Calculus II & 3 & MATH111 \\
\hline CMSC223 & Web Design & 3 & CMSC111 & PHYS222 & Physics II & 3 & PHYS211 \\
\hline CMSC311 & Comp Graphics \& G D & 3 & MATH122 & CMSC323 & Sc Research Skills & 2 & GCMS105 \\
\hline \multicolumn{8}{|c|}{$\Sigma$ CrHrs $=131$} \\
\hline
\end{tabular}

Course Code [11]: a 7-character code is adopted: (4 letters+3 digits) $\mathrm{a}_{4} \mathrm{a}_{3} \mathrm{a}_{2} \mathrm{a}_{1} \mathrm{~d}_{3} \mathrm{~d}_{2} \mathrm{~d}_{1}$

$\mathrm{a}_{4}-\mathrm{a}_{1}$ course or program code: 4 letters

$\mathrm{d}_{3}$ : level/year (1: 1 st yr,..., 4: 4th yr, ...)

$\mathrm{d}_{2}$ : semester: 1 for first semester, 2 for second semester

$\mathrm{d}_{1}$ : sequence of course within semester, GE or field

$\left(a_{4}={ }^{\prime} G ' \quad \& d_{2}=0\right.$ are used to indicate GE courses) 
CMSC Suggested program schedule distributed over semesters

\begin{tabular}{|c|c|c|c|c|c|c|c|c|c|}
\hline \multirow{2}{*}{$\begin{array}{l}\text { First Year } \\
\text { Course } \\
\text { Code }\end{array}$} & \multicolumn{4}{|l|}{ First Semester } & \multicolumn{5}{|c|}{ Second Semester } \\
\hline & Course Title & Th & $\operatorname{Pr}$ & $\begin{array}{l}\mathrm{Cr} \\
\mathrm{Hrs} \\
\end{array}$ & $\begin{array}{l}\text { Course } \\
\text { Code } \\
\end{array}$ & Course Title & Th & Pr & $\begin{array}{l}\mathrm{Cr} \\
\mathrm{Hrs}\end{array}$ \\
\hline CMSC111 & Prog Fundmntls I & 2 & 2 & 3 & CMSC121 & Prog Fundmntls II & 2 & 2 & 3 \\
\hline GKRD101 & Kurdish Language & 3 & - & 3 & GKRD102 & Kurdish History\&Culture & 3 & - & 3 \\
\hline GACD104 & Academic Debate & 3 & - & 3 & CMSC122 & Logic design & 2 & 2 & 3 \\
\hline MATH111 & Calculus I & 3 & - & 3 & MATH122 & Calculus II & 3 & - & 3 \\
\hline GENG103 & English Language & 3 & - & 3 & CMSC123 & Visual programming & 2 & 2 & 3 \\
\hline GCMS105 & Computer Skills & 2 & 2 & 3 & MATH123 & Discrete Structures & 3 & - & 3 \\
\hline & & \multicolumn{2}{|l|}{20} & 18 & & & \multicolumn{2}{|l|}{20} & 18 \\
\hline Second Yr & \multicolumn{4}{|l|}{ First Semester } & \multicolumn{5}{|c|}{ Second Semester } \\
\hline $\begin{array}{l}\text { Course } \\
\text { Code }\end{array}$ & Course Title & Th & $\operatorname{Pr}$ & $\begin{array}{l}\mathrm{Cr} \\
\mathrm{Hrs} \\
\end{array}$ & $\begin{array}{l}\text { Course } \\
\text { Code }\end{array}$ & Course Title & Th & Pr & $\begin{array}{l}\mathrm{Cr} \\
\mathrm{Hrs}\end{array}$ \\
\hline CMSC211 & Data Structures & 2 & 2 & 3 & CMSC221 & Algorithm A \& D & 2 & 2 & 3 \\
\hline CMSC212 & \begin{tabular}{|l|} 
Computer \\
Organization
\end{tabular} & 2 & 2 & 3 & CMSC222 & Computer Architecture & 2 & 2 & 3 \\
\hline MATH216 & \begin{tabular}{|l|} 
Probability \\
\&Statistics \\
\end{tabular} & 2 & 2 & 3 & CMSC223 & Web Design & 2 & 2 & 3 \\
\hline CMSC215 & Info. Management & 2 & 2 & 3 & CMSC224 & Database Systems & 2 & 2 & 3 \\
\hline CMSC216 & Programming Lang. & 2 & 2 & 3 & CMSC225 & Software Dev. & 2 & 2 & 3 \\
\hline PHYS211 & Physics I & 2 & 2 & 3 & \multirow{2}{*}{\multicolumn{2}{|c|}{\begin{tabular}{l|l} 
PHYS222 & Physics II \\
\end{tabular}}} & 2 & 2 & 3 \\
\hline & & \multicolumn{2}{|l|}{24} & 18 & & & \multicolumn{2}{|l|}{24} & 18 \\
\hline Third Yr & \multicolumn{4}{|l|}{ First Semester } & \multicolumn{5}{|c|}{ Second Semester } \\
\hline $\begin{array}{l}\text { Course } \\
\text { Code }\end{array}$ & Course Title & Th & $\operatorname{Pr}$ & $\begin{array}{l}\mathrm{Cr} \\
\mathrm{Hrs} \\
\end{array}$ & $\begin{array}{l}\text { Course } \\
\text { Code }\end{array}$ & Course Title & Th & $\operatorname{Pr}$ & $\begin{array}{l}\mathrm{Cr} \\
\mathrm{Hrs} \\
\end{array}$ \\
\hline CMSC311 & Comp Graphics\&G D & 2 & 2 & 3 & CMSC321 & Compilers & 2 & 2 & 3 \\
\hline CMSC312 & Theory of computation & 2 & - & 2 & CMSC322 & Android App Dev & 2 & 2 & 3 \\
\hline CMSC313 & Web Development & - & 4 & 2 & CMSC323 & Scientific Research Skills & 2 & - & 2 \\
\hline CMSC314 & Networking & 2 & 2 & 3 & CMSC324 & Data Security & 2 & 2 & 3 \\
\hline CMSC315 & Numerical analysis & 2 & 2 & 3 & CMSC325 & Summer Training* & - & - & 3 \\
\hline CMSC316 & Mini project I & - & 3 & 1 & CMSC326 & Mini project II & & 3 & 1 \\
\hline & & \multicolumn{2}{|l|}{23} & 14 & & & \multicolumn{2}{|l|}{17} & 15 \\
\hline Fourth Yr & \multicolumn{4}{|l|}{ First Semester } & \multicolumn{5}{|c|}{ Second Semester } \\
\hline $\begin{array}{l}\text { Course } \\
\text { Code }\end{array}$ & Course Title & Th & $\operatorname{Pr}$ & $\begin{array}{l}\mathrm{Cr} \\
\mathrm{Hrs}\end{array}$ & $\begin{array}{l}\text { Course } \\
\text { Code }\end{array}$ & Course Title & Th & $\operatorname{Pr}$ & $\begin{array}{l}\mathrm{Cr} \\
\mathrm{Hrs} \\
\end{array}$ \\
\hline CMSC411 & Intelligent Systems & 2 & 2 & 3 & & Technical Elective & 2 & 2 & 3 \\
\hline CMSC412 & Client -Server Net. & 2 & 2 & 3 & CMSC422 & Digital Image Processing & 2 & 2 & 3 \\
\hline CMSC413 & iOS App Dev & 2 & 2 & 3 & & Technical Elective & 2 & 2 & 3 \\
\hline CMSC414 & Operating Systems & 2 & 2 & 3 & & Technical Elective & 2 & 2 & 3 \\
\hline CMSC415 & CS Capstone Project I & - & 6 & 3 & \multirow{2}{*}{\multicolumn{2}{|c|}{$\mathrm{CrHrc}=131$}} & - & 6 & 3 \\
\hline & & \multicolumn{2}{|l|}{22} & 15 & & & \multicolumn{2}{|l|}{22} & 15 \\
\hline & & & & Tot & CrHrs $=131$ & & & & \\
\hline
\end{tabular}

*Summer Training is planned to be during the summer vacation. 
CMSC Course-PLO Alignment Matrix

\begin{tabular}{|c|c|c|c|c|c|c|c|c|c|c|c|c|}
\hline code & $\begin{array}{l}\text { drse } \\
\text { name }\end{array}$ & 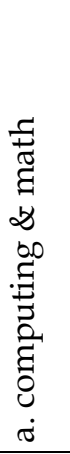 & 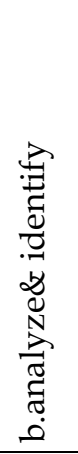 & 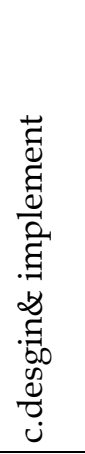 & 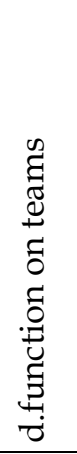 & 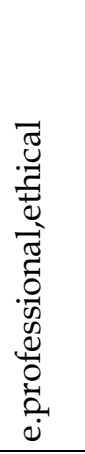 & 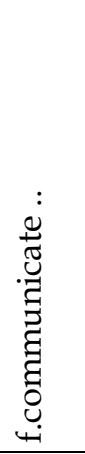 & 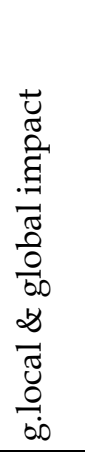 & 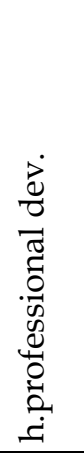 & 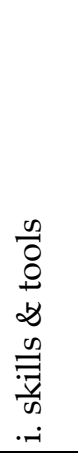 & 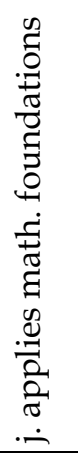 & 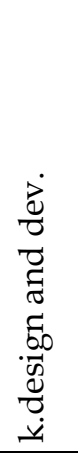 \\
\hline a...... & $\ldots \ldots$ & & & & & $\sqrt{ }$ & & & & & $\sqrt{ }$ & \\
\hline CMSC211 & Data Structures & $\sqrt{ }$ & $\sqrt{ }$ & & & & & & & $\sqrt{ }$ & & \\
\hline ........ & $\ldots \ldots$. & & & $\sqrt{ }$ & & & & & $\sqrt{ }$ & & & \\
\hline CMSC324 & Data Security & $\sqrt{ }$ & $\sqrt{ }$ & $\sqrt{ }$ & & $\sqrt{ }$ & & & & & & \\
\hline$\ldots \ldots \ldots$ & $\ldots \ldots$ & & & & & & $\sqrt{ }$ & & & & & $\sqrt{ }$ \\
\hline CMSC425 & CS Capstone Project II & $\sqrt{ }$ & $\sqrt{ }$ & $\sqrt{ }$ & $\sqrt{ }$ & $\sqrt{ }$ & $\sqrt{ }$ & $\sqrt{ }$ & $\sqrt{ }$ & $\sqrt{ }$ & $\sqrt{ }$ & $\sqrt{ }$ \\
\hline
\end{tabular}

\section{Appendix V Course Plan \& Course Report CAA Standards (2019): Annexes ${ }^{[8]}$}

\section{Annex 13: Course Syllabi (i.e. Course Plan)}

Each course syllabus should include:

a. course title and course code/number;

b. credit hours (or equivalent);

c. pre-requisites (if any) and co-requisites (if any);

d. name and contact information of instructor(s);

e. brief course description (as in the Catalog);

f. intended learning outcomes of the course;

g. linkage and contribution of course learning outcomes to the program outcomes;

h. course topics and contents on a week-by-week basis, including sessions for assessments;

i. scheduling of laboratory, studio, external visits and other non-lecture sessions, including online sessions, as appropriate;

j. information on out-of-class assignments with due dates for submission;

$\mathrm{k}$. methods and dates of examinations and other student assessments, including the relative weight of various assessment elements in determining the course grade;

1. teaching methods, including any use of online instruction;

m. course texts and recommended readings listed in standard bibliographic detail, and any other learning resources.

\section{Annex 16: Course Files}

Institutions maintain updated files for each course of instruction. These must contain sufficient information on each presentation of the course so that the faculty or other persons who evaluate program effectiveness can determine whether the course is meeting its learning outcomes, whether the course is being delivered in accordance with the syllabus, and whether changes to the course are appropriate.

Course files must be readily accessible to faculty and include the following information,

a. syllabi for the current and most recent previous offerings of the course, including any summer session offerings; 
b. copies of all instructor teaching materials;

c. copies of all assessment instruments;

d. instructor worked answers and marking schemes for all assessment instruments;

e. examples from across the range of student performance of graded responses to all assessment instruments;

f. student attendance data;

g. a comprehensive instructor review of the presentation of the course, covering:

$\square$ appropriateness of the course learning outcomes;

$\square$ extent to which the syllabus was covered;

$\square$ extent to which learning outcomes were met (with evidence);

$\square$ appropriateness of textbooks and other learning resources;

$\square$ appropriateness of assessment instruments in relation to learning outcomes;

$\square$ appropriateness of the balance of assessment;

$\square$ appropriateness of prerequisites;

$\square$ general comments on any problems encountered with the course;

h. quantitative analysis of student performance including individual student grades, both cumulative and for each assessment, and grade distribution;

i. summary of student feedback on the evaluation of the course;

j. instructor's proposals for any course improvements;

k. summary of actions taken to improve the course.

\section{Appendix VI Definition of Terms}

Capacity building: planned development of (or increase in) knowledge, output rate, management, skills, and other capabilities of an organization through acquisition, incentives, technology, and/or training.

CLO: course learning outcome, a statement of what learners are expected to be able to do on successful completion of a course in order to demonstrate their knowledge, understanding, skills and/or competences.

Course Catalog: includes general information on the institution, its resources and services, as well as academic information on its programs \& individual educational components.

CrHr: credit hour, one-hour lecture, or two/three-hour laboratory, over a 15-week semester are regarded as one $\mathrm{CrHr}$.

Formative Assessment: conducted during a performance/course/program with the purpose of providing feedback that can be used to modify, shape, and improve a performance/course/program.

OBE: a method of curriculum design and teaching that focuses on what students gained and can actually do after they are taught.

PEO: program educational objective, a broad statement that describes what graduates are expected to attain within a few years of graduation. PEOs are based on the needs of the program's constituencies. (ABET definition)

PLO: program learning outcome, is a statement of what learners are expected to know, understand or be able to do on successful completion of the entire program.

Psychometrics: assessment psychometrics is the measurement, analysis, and interpretation of performance across qualitative \& quantitative assessment, using the best available evidence to provide appropriate and defensible standards.

SCL: student centred learning, an approach to promote learning in communication with teachers and students and which takes students as active participants in their own learning.

Summative Assessment: done at the conclusion of a course or some larger instructional period (e.g., at the end of the program). The purpose is to determine success or to what extent the program/project/course met its goals. 